OPEN ACCESS

Edited by:

Francisco Ramos-Gomez, UCLA School of Dentistry,

United States

Reviewed by:

Sadeq Al-Maweri,

Al-Farabi College, Saudi Arabia

Cihad Dundar

Ondokuz Mayis University, Turkey

${ }^{*}$ Correspondence:

Ola B. Al-Batayneh

olabt@just.edu.jo

Specialty section:

This article was submitted to

Children and Health,

a section of the journal

Frontiers in Public Health

Received: 08 April 2019 Accepted: 18 October 2019 Published: 07 November 2019

Citation: Al-Batayneh OB, Al-Khateeb HO, Ibrahim WM and Khader YS (2019) Parental Knowledge and Acceptance of Different Treatment Options for Primary Teeth Provided by Dental Practitioners.

Front. Public Health 7:322. doi: 10.3389/fpubh.2019.00322

\section{Parental Knowledge and Acceptance of Different Treatment Options for Primary Teeth Provided by Dental Practitioners}

\author{
Ola B. Al-Batayneh ${ }^{1 *}$, Hanan O. Al-Khateeb ${ }^{1}$, Waiel M. Ibrahim ${ }^{1}$ and Yousef S. Khader ${ }^{2}$ \\ ${ }^{1}$ Pediatric Dentistry Division, Preventive Dentistry Department, Faculty of Dentistry, Jordan University of Science and \\ Technology, Irbid, Jordan, ${ }^{2}$ Department of Public Health and Epidemiology, Faculty of Medicine, Jordan University of Science \\ and Technology, Irbid, Jordan
}

Background: Parents have an influence on dental treatment options for young children regarding type of care provided. The aim of this study was to assess parents' knowledge and acceptance of different treatment options for primary teeth provided by dental practitioners for their children.

Materials and Methods: In this descriptive, cross-sectional study, caregiver/child dyads ( $n=476$ ) were recruited from patients at Pediatric Dental Clinics, Jordan University of Science and Technology. The data collection questionnaire to parents included: 1-demographic data 2-parental knowledge and practices regarding child's oral hygiene, caries and caries prevention 3-parental knowledge and acceptance of different treatment options for primary teeth including two given clinical scenarios (ICDAS-5 molar requiring intra-coronal restoration, ICDAS-6 molar requiring pulp therapy and stainless steel crown) with pictures before and after treatment. Afterwards, the child underwent a dental examination to record dmft/DMFT, gingival and plaque indices. Data was analyzed using SPSS, significance was set at $P \leq 0.05$.

Results: Children's ages were 2-12 years (mean/SD $6.97 \pm 2.5$ ); with 255/53.6\% males, $221 / 46.4 \%$ females. There were (166) children 2-5 years in primary dentition; $(108 / 166) 65 \%$ had ECC, and $(n=62 / 166) 37.4 \%$ had S-ECC, and (310) $6-12$ years in mixed dentition; (278/310) $89.7 \%$ had caries. Scaling and extraction were the highest known and accepted treatments for primary teeth by parents (35.5 and $30.1 \%$, respectively), while nitrous oxide/oxygen sedation was the least (3.6\%). Parental educational level was significant for composite restorations, fluoride gel application and pulp therapy $(P=0.03,0.02$, and 0.03 , respectively) and age above 40 for amalgam restorations $(P=0.04)$. In both scenarios, most parents preferred to leave any care decision in hands of the dentists with no effect of educational level $(P>0.05)$. There were $81.5 \%$ parents who reported that their children's dental status was good, however, 78.4\%/42.8\% children had an average dmft/DMFT score 5.34/2.32 and mean PI/GI scores $0.88 \pm 0.20 / 0.17 \pm 0.23$.

Conclusion: Parental knowledge and acceptance about dental treatment options for primary dentition was generally low. Parental education and age had an impact 
on parental knowledge and practices regarding child's oral hygiene, caries and caries prevention, and some treatment options. There was an overrated parental opinion of their child's teeth status despite the high dmft/DMFT and PI.

Keywords: parental knowledge and acceptance, treatment options, primary teeth, caries prevention, DMFT/dmft, children

\section{INTRODUCTION}

Oral health has an important role in the general well-being of individuals. The adoption of good oral health habits in childhood often takes place with parents, especially mothers $(1,2)$ and is affected by parental dental knowledge, attitudes, cultural beliefs and awareness about infant diet and feeding practices, oral hygiene habits, preventive regular dental visits, care of primary teeth and concern for oral health. It has been found that the more positive the parent's attitude is toward dentistry, then the better will be the dental health status of their children (3). Therefore, interventions targeting parental oral health beliefs and practices may be beneficial in the prevention of oral health problems.

Dental treatment of young children is usually provided only after explanation and consent with parents (4). There are a few studies on parental acceptance of dental treatment at the dental office for their children; some were limited to parental acceptance of dental treatment under general anesthesia or nitrous oxide, which was reported to be less than $10 \%$ for both (5); and acceptable in one third of parents in another study that evaluated acceptance of dental treatment under general anesthesia (6). In other studies, two scenarios were given to the parents to assess the acceptance of pulp therapy and restorative treatment, they found that most of the parents relied on the dentist to choose the treatment $(4,6,7)$, one-third refused to do any treatment for asymptomatic teeth $(4,6)$, and 9-37\% preferred tooth extraction for symptomatic teeth $(6,8)$.

Unfortunately, there is little information in the literature to show if parental age and education affects their preferences for the dental care of their children (6). The relationship between parental treatment preferences and factors such as their knowledge about oral hygiene, caries and caries prevention hasn't been fully investigated. Therefore, the aims of this study were:

(1) To assess parents' knowledge and acceptance of different treatment options for primary teeth provided by dental practitioners for their children.

(2) To assess parental knowledge and practices regarding the child's oral hygiene, caries and caries prevention.

\section{MATERIALS AND METHODS}

\section{Ethical Approval}

Ethical approval was gained from the IRB, JUST (Institutional Review Board, Jordan University of Science and Technology), grant \# 175/2014. In addition, written informed consent was obtained from all parents/caregivers after explanation of study objectives.

\section{Study Design, Setting, and Subjects}

This was a descriptive, cross-sectional study with a convenient sample of families that lived in North Jordan. The sample consisted of 476 subjects who were recruited from a group of parents accompanying their children to Pediatric Dental Clinics for free dental treatment at the Faculty of Dentistry, Jordan University of Science and Technology Irbid, Jordan between April, and December, 2014, respectively. Inclusion criteria for participation were: families of a healthy child, aged 2-12 years, with primary or mixed dentition, selected randomly among the family's children where the oldest or the youngest child was chosen sequentially in the consenting family.

\section{Data Collection}

The data were gathered by means of a self-reported questionnaire given for the primary caregiver (father or mother). A selfdesigned questionnaire in the local language (Arabic) was used. An investigator was responsible to choose a child randomly from each family after explaining the purpose of the study to the parent and giving instructions to completely fill the questionnaire specifically about the chosen child. Random choice of the child per family was based on choosing the only child, or choosing the eldest and youngest consecutively among each family with more than one child. Before data collection, the questionnaire was piloted twice, over a week interval, on 20 patients to ensure reproducibility, consistency and clarity; there was $95 \%$ agreement between the two times.

Two trained investigators (dentists), whose examination technique was calibrated, with (97.6\%) agreement, were responsible for the child examination. Inter-examiner and intra-examiner reproducibility was measured by re-examination of 20 children participating in the study with a 1-week interval between both examinations. The $k$-value of intra-examiner reliability was calculated to be (0.97). After that, the parent was met to explain the oral health of the examined child and to clarify findings of the examination.

\section{The Questionnaire and Clinical Scenarios}

A questionnaire was used to collect the data in the form of 30 close-ended multiple-choice questions. The questions were split into three sections.

Section 1: demographic data

Section 2: parental knowledge and practices regarding the child's oral hygiene, caries and caries prevention

Section 3: parental knowledge and acceptance of different treatment options for primary teeth and parental opinion toward two given clinical scenarios (Figures 1,2). 

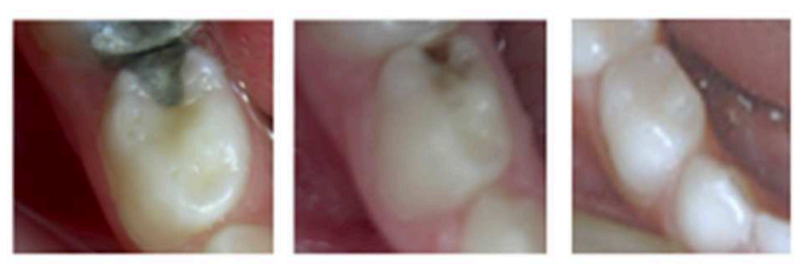

FIGURE 1 | Restorative treatment ICDAS 5- "If your child has a carious asymptomatic primary tooth that needed to be restored, will you accept dental treatment or not? And if you accept the treatment, will you leave the decision of the material to be used to the dentist or will you choose between amalgam and composite?" Results: $60.3 \%$ of participants preferred to leave any care decision in the hands of the dentists, and there was no difference between university educated and secondary school level educated parents $(P=0.09)$. A few parents $(8.4 \%)$ did not want any treatment to be provided since the tooth was primary and symptom-free.

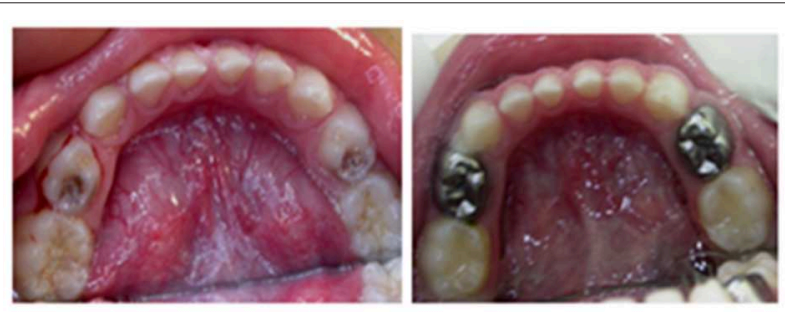

FIGURE 2 | Restorative treatment ICDAS 6- Pulp therapy and Stainless steel crown-"If your child has a carious primary tooth which is causing toothache and needs pulp therapy and a stainless steel crown, will you accept dental treatment or will you choose to extract the tooth or leave it as it is? Results: $72.9 \%$ of the parents accepted the treatment option given by the dentist but $16.8 \%$ did not want any treatment. Around $11.3 \%$ of parents preferred the tooth to be extracted. Parental educational level did not play a significant role in their preferences for treatment $(P=0.58)$. Comparisons in parental choices for both clinical scenarios were not significant between children age groups $(<6,6-12)$ or gender.

\section{Examination of the Child}

From each family, the randomly selected child was fully examined intra-orally using a sterile dental front mirror and a periodontal probe (Michigan O probe with William's coding) to record dental caries, modified O'leary gingival and plaque indices $(0$ $=$ absence, $1=$ presence on sextant primary teeth). Dental caries was recorded at baseline using WHO Oral Health Survey Basic Methods 1997 criteria; dmft/DMFT index revealed decayed $(\mathrm{d} / \mathrm{D})$, missing/extracted $(\mathrm{m} / \mathrm{M})$ and filled $(\mathrm{f} / \mathrm{F})$ teeth $(\mathrm{t} / \mathrm{T})$ in deciduous/permanent teeth (9). The modified index was used in previous studies (10) and was based on the O'Leary index (11) and The Plaque Assessment Scoring System (12) was used in obtaining the plaque index (PI) score. Measurements were obtained by recording plaque deposits on all surfaces (buccal, lingual, mesial and distal) of the following teeth: 16/55, $21 / 61,24 /$ either 64 or $63,46 / 85,41 / 81,44 / 84$. If plaque was visible on the probe, the surface was counted as positive for plaque accumulation and given a score of 1 for plaque presence at that surface otherwise a score of 0 for no plaque.
There were 24 possible plaque surfaces per patient. Gingival index (GI) scores were obtained for the teeth using the same method in scoring PI. Gingivitis was considered present if there was bleeding on probing clinically. The plaque/ gingival index for the child is the percentage of surfaces positive for plaque/gingivitis. For both indices, the score of the patient would range between 0 and 1 . Based on a previous study, patients were considered not to have plaque or gingivitis if the score was between 0 and 0.13 ; if the score of patients was from 0.17 to 1.0 they were considered to have plaque, calculus or gingivitis (10). Subjects were rewarded for cooperative behavior by gifts.

\section{Sample Size Calculation}

The sample size was calculated assuming that $50 \%$ of parents had proper knowledge and practices regarding child's oral hygiene, caries and caries prevention. The assumption of $50 \%$ was used to yield the largest sample size. At a power of $80 \%$ and level of significance of 0.05 , the sample needed was estimated at 385 for estimating the expected proportion with $5 \%$ absolute precision.

\section{Statistical Analysis}

Data entry and statistical analysis were done using Statistical Package for the Social Sciences (SPSS version 25.0) for windows (SPSS Inc., Chicago, USA). Means and standard deviations for the variables were calculated. The Chi-square test was used to compare percentages. Multivariate analysis using binary logistic and multinomial regression was conducted to test the differences in parental knowledge and practices according to parental age and education. A $P \leq 0.05$ was considered statistically significant.

\section{RESULTS}

The response rate was $91.5 \%(n=526 / 575)$. Of the 526 parents/children who participated in this study, 50 forms were excluded due to incomplete data or examination. The remaining 476 forms were analyzed. Parental demographic data are shown in Table 1. The children's ages ranged between 2 and 12 years with a mean (SD) age of 6.97 (2.5) years. Of the total examined children, 255 were males $(53.6 \%)$ and 221 were females (46.4\%). For the sake of analysis, the children were divided into two groups; ages $<6$, years $(n=166$ children, with primary dentition), and ages $6-12$ years ( $n=310$, in the mixed dentition).

Parental knowledge and practices toward their children's oral hygiene at home is shown in Table 2. Comparing between children age groups $(<6,6-12$ years), differences existed in choosing the age appropriate toothpaste $\left(\mathrm{x}^{2}=\right.$ $11.1 ; p<0.001)$, correct tooth brushing technique $\left(\mathrm{x}^{2}\right.$ $=78.5, p \leq 0.001$ ), caregiver supervision during tooth brushing $\left(\mathrm{x}^{2}=8.1, p=0.004\right)$, and additional teeth cleaning methods $\left(x^{2}=9.3, p=0.002\right)$. In the multivariate analysis, parents aged 20-40 years and those with university education had significantly better knowledge and practices toward children's oral hygiene at home with regards to 
having a toothbrush, brushing frequency and supervision during brushing.

Parental knowledge of caries and caries prevention is shown in Table 3. Parental opinion about their child's teeth was rated as good by $81.5 \%$. Parents of the two age groups differed significantly in their knowledge about missing school days due to toothache $\left(\mathrm{x}^{2}=21.6, p<0.001\right)$, reason for visiting the dentist $\left(\mathrm{x}^{2}=59.5, p<0.001\right)$, and fluoride sources $\left(\mathrm{x}^{2}=6.0, p=\right.$ 0.048). Parental knowledge about caries and caries prevention regarding effect of dental caries and periodontal problems on general health and fluoride effect on teeth was significantly better in university educated parents compared to secondary school educated parents in the univariate and multivariate analysis. Age was not a significant factor with regards to any of the variables in Table 3.

TABLE 1 | Parental demographic data according to children's age (years), total sample $n=476$ ( $<6$ years old $=166,6-12$ years old $=310$ ), $\%$ are based on the total sample size.

\begin{tabular}{cccc}
\hline Variable & Father N (\%) & & Mother N (\%) \\
\cline { 2 - 3 } & Children $<6 \quad$ Children 6-12 & & Children $<6 \quad$ Children 6-12
\end{tabular}

\begin{tabular}{|c|c|c|c|c|}
\hline \multicolumn{5}{|l|}{ Age (years) } \\
\hline $20-40$ & $54(11.3)$ & $82(17.2)$ & 93 (19.5) & $123(25.8)$ \\
\hline Total & \multicolumn{2}{|c|}{$136(28.6)$} & \multicolumn{2}{|c|}{$216(45.4)$} \\
\hline More than 40 & $14(2.9)$ & $74(15.5)$ & $5(1.1)$ & $31(6.5)$ \\
\hline Total & \multicolumn{2}{|c|}{88 (18.5) } & \multicolumn{2}{|c|}{$36(7.6)$} \\
\hline \multicolumn{5}{|l|}{ Education } \\
\hline Secondary school & $22(4.6)$ & $41(8.6)$ & $31(6.5)$ & 68 (14.3) \\
\hline Total & \multicolumn{2}{|c|}{63 (13.2) } & \multicolumn{2}{|c|}{99 (20.8) } \\
\hline University & $46(0.97)$ & $115(24.2)$ & $67(14.1)$ & $86(18.1)$ \\
\hline Total & \multicolumn{2}{|c|}{$161(33.8)$} & \multicolumn{2}{|c|}{$153(32.1)$} \\
\hline Total $=476$ & \multicolumn{2}{|c|}{224} & \multicolumn{2}{|c|}{252} \\
\hline
\end{tabular}

Parental knowledge and acceptance of different treatment options of the primary teeth by parents is shown in Table 4. From the provided treatment option list, scaling and extraction were the highest known and accepted treatment by the parents (35.5 and $30.1 \%$, respectively), while treatment under nitrous oxide/ oxygen sedation was the least (3.6\%). Comparisons between parental knowledge and acceptance of treatment options were not significant for both children age groups $(<6,6-12)$ and gender. There was no significant difference in knowledge and acceptance of all the treatment options among the participants according to parental educational level except for composite restorations, fluoride gel application and pulp therapy, where university educated parents knew and accepted those two treatment options more $(P=$ $0.03,0.02$, and 0.03 , respectively). With regards to age, those who were above 40 years had significantly more knowledge and acceptance of amalgam restorations than those between 20 and 40 years $(P=0.04)$. The findings of the multivariate analysis were consistent with the findings of the univariate analysis.

Responses of parents to the clinical scenarios are indicated in the figure legends of Figures 1, 2. Regarding the importance of dental treatment for the primary dentition as compared to permanent teeth, $55 \%$ of the parents stated that primary teeth will be replaced and no need to do any dental treatment. As to whether parents had enough information about oral health of their children, $91.6 \%$ of parents were interested in receiving more information about the primary dentition.

The number of decayed, filled and missing teeth were summed together to give the DMFT score for the permanent dentition and the $\mathrm{dmft}$ score for the primary dentition (Table 5). The mean dmft and DMFT for the children was 4.64 (SD 3.95) and 1.08 (SD 1.47), respectively. Only $58(12.2 \%)$ of children had $\mathrm{dmft}$ $=0$, and $32(6.7 \%)$ children had DMFT $=0$. The modified O'leary plaque index mean was 0.88 (SD 0.20) with a maximum score of 1 in $66.2 \%$ children and a minimum score of 0 in

TABLE 2 | Parental knowledge and practices toward their children's oral hygiene at home.

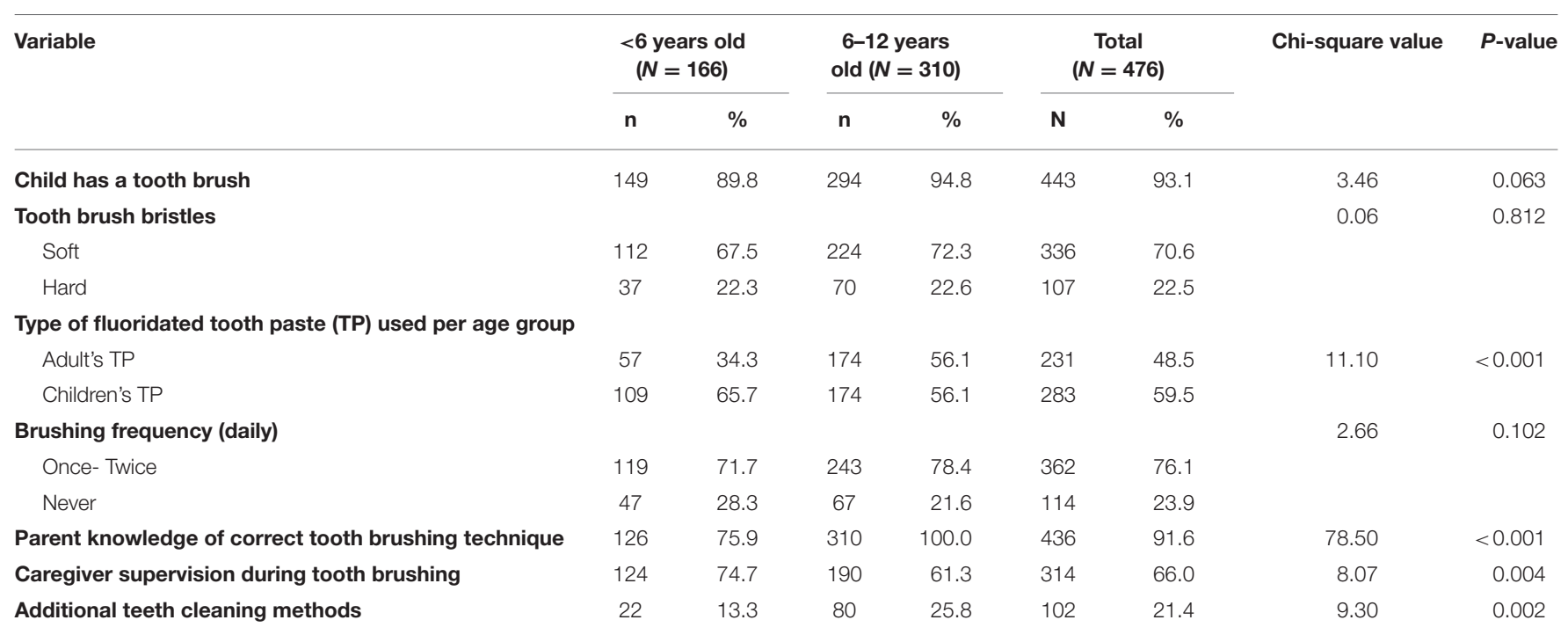


TABLE 3 | Parental knowledge of caries and caries prevention.

\begin{tabular}{|c|c|c|c|c|c|c|c|c|}
\hline \multirow[t]{2}{*}{ Variable } & \multicolumn{2}{|c|}{$\begin{array}{c}<6 \text { years old } \\
(N=166)\end{array}$} & \multicolumn{2}{|c|}{$\begin{array}{c}6-12 \text { years } \\
\text { old }(N=310)\end{array}$} & \multicolumn{2}{|c|}{$\begin{array}{c}\text { Total } \\
(N=476)\end{array}$} & \multirow[t]{2}{*}{ Chi-square value } & \multirow[t]{2}{*}{$P$-value } \\
\hline & $\mathbf{n}$ & $\%$ & $\mathbf{n}$ & $\%$ & $\mathbf{N}$ & $\%$ & & \\
\hline Opinion about children's teeth status & & & & & & & 4.6 & 0.031 \\
\hline Good & 144 & 86.7 & 244 & 78.7 & 388 & 81.5 & & \\
\hline Poor & 22 & 13.3 & 66 & 21.3 & 88 & 18.5 & & \\
\hline Opinion about the reason for dental decay & & & & & & & 2.5 & 0.417 \\
\hline Sugar consumption & 42 & 25.3 & 83 & 26.8 & 125 & 26.3 & & \\
\hline Poor oral hygiene & 12 & 7.2 & 36 & 11.6 & 48 & 10.1 & & \\
\hline Both & 101 & 60.8 & 170 & 54.8 & 271 & 56.9 & & \\
\hline Don’t know & 11 & 6.6 & 21 & 6.8 & 32 & 6.7 & & \\
\hline General health is affected by dental caries and periodontal disease & 127 & 76.5 & 238 & 76.8 & 365 & 76.7 & 0.001 & 0.968 \\
\hline Missing school days due to toothache & 26 & 15.7 & 113 & 36.5 & 139 & 29.2 & 21.6 & $<0.001$ \\
\hline Fluoride sources & & & & & & & 6.0 & 0.048 \\
\hline Tooth paste & 77 & 46.4 & 180 & 58.1 & 257 & 54.0 & & \\
\hline Drinking water & 42 & 25.3 & 58 & 18.7 & 100 & 21.0 & & \\
\hline Don't know & 47 & 28.3 & 72 & 23.2 & 119 & 25.0 & & \\
\hline Fluoride effect on teeth & & & & & & & 0.5 & 0.758 \\
\hline Whitening teeth & 28 & 16.9 & 57 & 18.4 & 85 & 17.9 & & \\
\hline Strength and caries resistance & 108 & 65.1 & 191 & 61.6 & 299 & 62.8 & & \\
\hline Don't know & 30 & 18.1 & 62 & 20.0 & 92 & 19.3 & & \\
\hline Reason for visiting the dentist & & & & & & & 59.5 & $<0.001$ \\
\hline Dental pain & 73 & 44.0 & 220 & 71.0 & 293 & 61.6 & & \\
\hline Check up & 15 & 9.0 & 45 & 14.5 & 60 & 12.6 & & \\
\hline Never been there & 78 & 47.0 & 45 & 14.5 & 123 & 25.8 & & \\
\hline Knowledge about pediatric dentistry specialty & & & & & & & 2.29 & 0.318 \\
\hline Yes, and treat there & 71 & 42.8 & 147 & 47.4 & 218 & 45.8 & & \\
\hline Yes, but treat with general practitioner & 58 & 34.9 & 111 & 35.8 & 169 & 35.5 & & \\
\hline Don't know & 37 & 22.3 & 52 & 16.8 & 89 & 18.7 & & \\
\hline
\end{tabular}

TABLE 4 | Parental knowledge and acceptance of different treatment options in primary teeth.

\begin{tabular}{lccc}
\hline Treatment option & Knowledge & Acceptance & $\begin{array}{c}\text { Knowledge and } \\
\text { acceptance }\end{array}$ \\
\hline Scaling & $53.6 \%$ & $48.8 \%$ & $35.5 \%{ }^{* *}$ \\
Fissure Sealant & $9 \%$ & $13.9 \%$ & $5.4 \%^{*}$ \\
Fluoride Gel Application & $27.1 \%$ & $30.7 \%$ & $18.7 \%$ \\
Composite Restoration & $36.1 \%$ & $42.2 \%$ & $23.5 \%$ \\
Amalgam Restoration & $28.3 \%$ & $27.7 \%$ & $17.5 \%$ \\
Pulp therapy & $13.9 \%$ & $12 \%$ & $7.2 \%{ }^{*}$ \\
Stainless steel Crown & $11.4 \%$ & $14.5 \%$ & $6 \%{ }^{*}$ \\
Extraction & $48.8 \%$ & $41.6 \%$ & $30.1 \%{ }^{* *}$ \\
Space Maintainer & $26.5 \%$ & $31.3 \%$ & $18.7 \%$ \\
Nitrous oxide Sedation & $6 \%$ & $10.2 \%$ & $3.6 \%{ }^{*}$ \\
General Anesthesia & $15.7 \%$ & $24.7 \%$ & $8.4 \%$ \\
Dental Radiographs & $34.9 \%$ & $43.4 \%$ & $27.1 \%$ \\
\hline
\end{tabular}

*Treatments less known and accepted by the parents.

${ }^{\star *}$ Treatments most known and accepted by the parents.

$0.2 \%$ which was in one child. Moreover, the modified O'leary gingival index mean was 0.16 (SD 0.23 ) with a maximum score of 1 in $2.3 \%$ and a minimum score of 0 in $50.8 \%$ of children.
Of the $81.5 \%$ parents who reported that their children's dental status was good, only 21.6 and $57.2 \%$ had dmft and DMFT $=0$, while 78.4 and $42.8 \%$ had an average $\mathrm{dmft} / \mathrm{DMFT}$ score of 5.34/2.32. However, the PI and GI $=0$ was present in 11.9 and $74.2 \%$.

\section{DISCUSSION}

The preservation of healthy teeth is one of the key health issues in childhood and parents play an important role in their children's oral health. Parental education played a significant role in knowledge and practices toward children's oral hygiene at home with regards to having a toothbrush, brushing frequency and supervision during brushing. A high percentage of children in the sample were reported to brush their teeth at least once to twice daily, similar results were found in other studies (1416), and the brushing frequency was more when the parents were university educated, similar to that reported by Rajab (17). More than half of the total sample of parents guided and supervised their children while brushing their teeth (Table 2) and this was similar to other's findings (18). The use of additional measures was low in our sample, similar to other studies $(16,19)$, and this could be attributed to the lack of knowledge of benefits of 
TABLE 5 | Average DMFT/dmft table for children in the sample by age (years), total sample $n=476$ ( $<6$ years old $=166,6-12$ years old $=310$ ), $\%$ are based on the total sample size.

\begin{tabular}{|c|c|c|c|c|}
\hline \multicolumn{2}{|c|}{ Age of child } & \multirow{2}{*}{$\begin{array}{l}\text { Average DMFT/dmft } \\
\text { Average } \mathrm{dmft}=0\end{array}$} & \multirow{2}{*}{$\begin{array}{c}\mathbf{N}(\%) \\
18(3.8)\end{array}$} & \multirow{2}{*}{$\begin{array}{l}\text { Diagnosis } \\
\text { Caries free }\end{array}$} \\
\hline$<6$ years old & $2-3$ years & & & \\
\hline$(n=166)$ & 40 (8.4\%) & Average dmft $=1.6$ & $11(2.3)$ & $\begin{array}{l}\text { Dental caries } \\
(E C C)^{\star}\end{array}$ \\
\hline & & Average $\mathrm{dmft} \geq$ age +1 & $11(2.3)$ & $\mathrm{S}-\mathrm{ECC}^{\star \star}$ \\
\hline & $4-5$ years & Average $\mathrm{dmft}=0$ & $40(8.4)$ & Caries free \\
\hline & $126(26.5)$ & Average $\mathrm{dmft}=2.9$ & $35(7.4)$ & $\begin{array}{l}\text { Dental caries } \\
(E C C)^{*}\end{array}$ \\
\hline & & Average dmft $\geq$ age +1 & $51(10.7)$ & S-ECC ${ }^{\star \star}$ \\
\hline \multirow{2}{*}{$\begin{array}{l}6-12 \text { years } \\
\text { old }\end{array}$} & $6-12$ years & Average $\mathrm{DMFT} / \mathrm{dmft}=0$ & $32(6.7)$ & Caries free \\
\hline & $310(65.1)$ & Average DMFT/dmft $=5.5$ & $\begin{array}{c}278 \\
(58.4)\end{array}$ & Dental caries \\
\hline
\end{tabular}

\section{Total}

476

${ }^{\star}$ ECC: Early Childhood Caries defined as presence of 1 or more decayed (non-cavitated or cavitated lesions), missing (due to caries), or filled tooth surfaces in any primary tooth in a child 71 month of age or younger (13).

${ }^{*} S$-ECC: Any sign of smooth-surface caries in children younger than 3 years of age. From age 3 through 5, 1 or more cavitated, missing (due to caries), or filled smooth surfaces in primary maxillary anterior teeth or a decayed, missing, or filled score of $\geq 4$ (age 3), $\geq 5$ (age 4), $\geq 6$ (age 5) surfaces (13).

these auxiliary methods $(15,16,19,20)$. Studies in Jordan on early childhood caries revealed several risk factors associated with caries in children. Some of these factors included; infant feeding habits, oral hygiene practices and socioeconomic status (17, 21, 22). Regarding socioeconomic status there were conflicting results about its actual impact on ECC in Jordan (22-25). Yet, no indices were used to measure oral hygiene and plaque scores and their association with ECC in these studies (26).

In relation to parental knowledge about caries and caries prevention, most of the parents in both age groups recognized the sources of fluoride and its effect on teeth and many of the parents reported that poor oral hygiene and high sugar consumption were the causes for dental decay and this is consistent with other studies $(16,17,20)$, and indicates good knowledge about causes of teeth decay. Again, parental education was significantly related to knowledge about effect of dental caries and periodontal problems on general health and fluoride effect on teeth. A high proportion of the subjects reported that children's bad oral health could affect the general health which implies that their children's oral health should be in a good status, however, this wasn't the case since $\mathrm{dmft} / \mathrm{DMFT}$ was $4.64 / 1.08$. Similar to previous studies $(16,18-$ 20) parents reported that pain was the main reason for visiting the dental office instead of regular check-up.

The lack of knowledge of parents about different treatment options for primary teeth, especially treatment under general anesthesia or nitrous oxide/oxygen sedation that are used in special situations for pediatric patients could be attributed to fear and low dental awareness (5, 6). Additionally, knowledge regarding pulp therapy and stainless steel crowns for primary teeth was found to be very low, and this explains the low parental acceptance of the treatment with these two options and the impact of parental education which was significant compared to those who have less education. Preventive treatment options that can be provided for children such as fissure sealants were neither known by parents nor accepted opposite to what was found in other countries such as in Australia (27), and this could partially explain the high $\mathrm{dmft} / \mathrm{DMFT}$ and plaque index in the children and the highest knowledge and acceptance for scaling and extraction. Parental education was significantly important in those who recognized fluoride gel application and accepted it as a treatment. Regarding dental filling materials, composite restorations were significantly more known and accepted by university educated parents and those in the 20-40 age group more than amalgam restorations, which indicated that aesthetic was more of a concern than other factors that influence the restoration material selection in this group of participants (28). The need for more knowledge about primary dentition preservation and treatment was in agreement with other studies $(29,30)$, indicating that more attention should be given for dental educational programs for parents and children.

In the two given scenarios, the majority of parents were happy to leave the decision about the treatment to the dentist and parental educational level or age did not play a significant role in their preferences for treatment. The reliance of parents on dentist for decision on the choice of their children's dental treatment suggested the need for dental health education to both parents and children on dental treatment $(4,6,7)$. Notably, $91.6 \%$ of parents were interested in receiving more information about the primary dentition. In the asymptomatic carious primary tooth scenario, studies showed that some parents refused any treatment to be provided for a primary tooth as it will be replaced by a permanent successor $(4,6,20,29)$. In the second scenario were the child had a carious primary tooth with toothache requiring pulp therapy and stainless steel crown, some parents decided that the best treatment to be provided for this primary tooth was the extraction to relieve the pain as found by other studies $(6,8)$. Some parents in other studies reported that primary teeth were important and should be preserved $(18,31)$.

The poor status of the children's teeth in terms of mean $\mathrm{dmft} / \mathrm{DMFT}$ scores and plaque index didn't correlate with parental assessment of their child's oral health. Of parents who reported that their children's dental status was good, 78.4 and $42.8 \%$ had an average dmft/DMFT score 5.34/ 2.32. Studies in Jordan showed that the overall prevalence of early childhood caries ranges between 48 and $72 \%(22-24,32)$. The plaque index in most children (66.2\%) was 1 which indicates presence of dental plaque when the children were examined; this reflects poor oral hygiene practices and predicts more caries and more gingival problems at a young age $(6,15,33,34)$.

There were some limitations for this study as it relied on a self-constructed questionnaire that lacked content and construct validity and was a single center study that didn't assess different regions in Jordan and other socio-economic factors that could have affected the choices by the parents. In addition, Berkson error could have been caused as the study was carried out on patients admitted to a clinic, and results could be subject to bias report given the nature of the study (questionnaire-based) and selection bias, and factors such as differences in maternal and paternal perception of choices of treatment since any of the parents answered the questionnaire based on who attended with the child. On the other hand, a relatively high number of subjects, compliance between observers, clear evaluation criteria 
and extensive sociodemographic data were the strengths of the study. In conclusion, parental knowledge and acceptance about dental treatment options for primary dentition was generally low. Parental education and age had an impact on parental knowledge and practices regarding the child's oral hygiene, caries and caries prevention, and some treatment options. There was an overrated parental opinion of their child's teeth status despite the high dmft/DMFT, PI and GI in the children. This reflects the need of more effective communication between dental professionals and parents in addition to public preventive and educational programs in order to educate them how to take care of their child's oral health, the importance of regular dental visits and including parents in the decision of treatment instead of the total reliance on dental professionals which could be a recommendation for future studies.

\section{DATA AVAILABILITY STATEMENT}

All datasets generated for this study are included in the article/supplementary material.

\section{REFERENCES}

1. Inglehart $\mathrm{M}$, Tedesco LA. Behavioural research related to oral hygiene practices: new century model of oral health promotion. Periodontology. (2000) 8:15-23. doi: 10.1111/j.1600-0757.1995.tb00042.x

2. Abiola AA, Eyitope OO, Sonny JO, Folayan MO. Do maternal factors influence the dental health status of Nigerian pre-school children? Int J Paediatr Dent. (2009) 19:448-54. doi: 10.1111/j.1365-263X.2009.01019.x

3. Okada M, Kawamura M, Kaihara Y, Matsuzaki Y, Kuwahara S, Ishidori H, et al. Influence of parents' oral health behaviour on oral health status of their school children: an exploratory study employing a causal modelling technique. Int J Paediatr Dent. (2002) 12:101-8. doi: 10.1046/j.1365-263X.2002.00338.x

4. Tickle M, Milsom K, King D, Kearney-Mitchell P, Blinkhorn A. The fate of the carious primary teeth of children who regularly attend the general dental service. Br Dent J. (2003) 192:219-23. doi: 10.1038/sj.bdj.4801338

5. Boka V, Arapostathis K, Vretos N, Kotsanos N. Parental acceptance of behaviour-management techniques used in paediatric dentistry and its relation to parental dental anxiety and experience. Eur Arch Paediatric Dent. (2014) 15:333-9. doi: 10.1007/s40368-014-0119-y

6. Tickle M, Milsom KM, Humphris GM, Blinkhorn AS. Parental attitudes to the care of the carious primary dentition. Br Dent J. (2003) 195:451-5; discussion 449. doi: 10.1038/sj.bdj.4810600

7. Popoola BO, Kloude B, Denlove OO. Parental attitudes to the care of the carious primary dentition experience from a Nigerian tertiary hospital. Afr J Med Sci. (2013) 42:65-71.

8. Hussein A, Abu-Hassan M, Schroth R, Ghanim A. Parent's perception on the importance of their children's first dental visit: a cross-sectional pilot study in Malaysia. J Oral Res. (2013) 2013:17-25. doi: 10.12816/0012189

9. World Health Organization. Oral Health Surveys, Basic Methods. Geneva: World Health Organization (2013).

10. Al Jamal G, Al-Batayneh O, Hamamy D. The alveolar bone height of the primary and first permanent molars in healthy 6 to 9-year-old Jordanian children. Int J Paediatr Dent. (2011) 21:151-9. doi: 10.1111/j.1365-263X.2010.01073.x

11. O'Leary TJ, Drake RB, Naylor JE. The plaque control record. J Periodontol. (1972) 43:38. doi: 10.1902/jop.1972.43.1.38

12. Butler BL, Morejon O, Low SB. An accurate, time-efficient method to assess plaque accumulation. J Am Dent Assoc. (1996) 127:17636. doi: $10.14219 /$ jada.archive.1996.0137

\section{ETHICS STATEMENT}

Ethical approval was gained from the IRB, JUST (Institutional Review Board, Jordan University of Science and Technology), grant \# 175/2014. In addition, written informed consent was obtained from all parents/caregivers after explanation of study objectives.

\section{AUTHOR CONTRIBUTIONS}

OA-B conceived the research idea, designed the study, and wrote up the manuscript. HA-K performed data collection and data entry. WI assisted in data collection and YK performed data analysis. All authors agreed on the final manuscript.

\section{ACKNOWLEDGMENTS}

This project was funded by the Deanship of Scientific Research, at Jordan University of Science and Technology, Irbid 22110, Jordan (grant \# 20140175).

13. American Academy of Pediatric Dentistry. Definition of Early Childhood Caries (ECC). (2008). Retrieved from: http://www.aapd.org/assets/1/7/d_ecc. pdf

14. Gussy MG, Waters EB, Riggs EM, Lo SK, Kilpatrick NM. Parental knowledge, beliefs and behaviours for oral health of toddlers residing in rural Victoria. Aust Dent J. (2008) 53:52-60. doi: 10.1111/j.1834-7819.2007.00010.x

15. Folayan MO1, Kolawole KA, Oyedele T, Chukwumah NM, Onyejaka N, Agbaje H, Oziegbe EO, Oshomoji OV. Association between knowledge of caries preventive practices, preventive oral health habits of parents and children and caries experience in children resident in sub-urban Nigeria. BMC Oral Health. (2014) 14:156. doi: 10.1186/1472-6831-14-156

16. Al-Omiri MK, Al-Wahadni AM, Saeed KN. Oral health attitudes, knowledge, and behavior among school children in north Jordan. I Dent Educ. (2006) 70:179-87.

17. Rajab LD, Petersen PE, Bakaeen G, Hamdan MA. Oral health behaviour of schoolchildren and parents in Jordan. Int J Paediatr Dent. (2002) 12:16876. doi: 10.1046/j.1365-263X.2002.00359.x

18. Thakare VG, Ajith Krishnan CG, Chaware S. Parents' perceptions of factors influencing the oral health of their preschool children in Vadodara city, Gujarat: a descriptive study. Eur J Gen Dent. (2012) 1:449. doi: 10.4103/2278-9626.101359

19. Saldunaite K, Bendoraitiene EA, Slabšinskiene E, Vasiliauskiene I, Andruškevičiene V, Zubiene $J$. The role of parental education and socioeconomic status in dental caries prevention among Lithuanian children. Medicina. (2014) 50:156-61. doi: 10.1016/j.medici.2014.07.003

20. Chhabra N, Chhabra A. Parental knowledge, attitudes and cultural beliefs regarding oral health and dental care of preschool children in an Indian population: a quantitative study. Eur Arch Paediatric Dent. (2012) 13:7682. doi: $10.1007 / \mathrm{BF} 03262848$

21. Sayegh A, Dini EL, Holt RD, Bedi R. Oral health, socio-demographic factors, dietary and oral hygiene practices in Jordanian children. J Dent. (2005) 33:379-88. doi: 10.1016/j.jdent.2004.10.015

22. Janson S, Fakhouri H. Dental health in suburban Jordanian pre- school children. Swed Dent J. (1993) 17:123-7.

23. Rajab LD, Hamdan MA. Early childhood caries and risk factors in Jordan. Commun Dent Health. (2002) 19:224-9.

24. Sayegh A, Dini EL, Holt RD, Bedi R. Caries prevalence and patterns and their relationship to social class, infant feeding and oral hygiene in 4-5-year-old children in Amman, Jordan. Commun Dent Health. (2002) 19:144-51. 
25. Sayegh A, Dini EL, Holt RD, Bedi R. Food and drink consumption, sociodemographic factors and dental caries in 4-5-year-old children in Amman, Jordan. Br Dent J. (2002) 193:37-42. doi: 10.1038/sj.bdj.4801478a

26. Al-Batayneh OB. Chapter 17: Jordan. In: Folayan M, editor. A Compendium on Oral Health of Children around the World: Early Childhood Caries. Oxford: Nova Science Publishers (2018). p. 207-20.

27. Mafeni JO, Messer LB. Parental knowledge and attitudes towards pit and fissure sealants. Aust Dent J. (1994) 39:17280. doi: 10.1111/j.1834-7819.1994.tb03088.x

28. Peretz B, RamD. Restorative material for children's teeth: preferences of parents and children. J Dent Child. (2002) 69:243-8.

29. Chan SC, Tsai JS, King NM. Feeding and oral hygiene habits of preschool children in Hong Kong and their caregivers' dental knowledge and attitudes. Int J Paediatr Dent. (2002) 12:322-31. doi: 10.1046/j.1365-263X.2002.00389.x

30. Naidu R, Nunn J, Forde M. Oral healthcare of preschool children in Trinidad: a qualitative study of parents and caregivers. BMC Oral Health. (2012) 12:27. doi: 10.1186/1472-6831-12-27

31. Halon G, Abu Rahme M, Ram D. Parents' attitude toward their children's appearance in the case of esthetic defects of the anterior primary teeth. J Clin Pediatr Dent. (2009) 34:141-5. doi: 10.17796/jcpd.34.2.910037663v $7 \mathrm{pm} 6 \mathrm{vg}$
32. Hattab FN, Al- Omari MA, Angmar-Mansson B, Daoud N. The prevalence of nursing caries in one -to- four- year- old children in Jordan. ASDC J Dent Child. (1999) 66:53-8.

33. Bozorgmehr E, Hajizamani A, Mohammadi T. Oral health behavior of parents as a predictor of oral health status of their children. ISRN Dentistry. (2013) 2013:741783. doi: 10.1155/2013/741783

34. Rajab LD, Petersen PE, Baqain Z, Bakaeen G. Oral health status among 6and 12-year-old Jordanian schoolchildren. Oral Health Prev Dent. (2014) 2:99-107. doi: 10.3290/j.ohpd.a31220

Conflict of Interest: The authors declare that the research was conducted in the absence of any commercial or financial relationships that could be construed as a potential conflict of interest.

Copyright (c) 2019 Al-Batayneh, Al-Khateeb, Ibrahim and Khader. This is an openaccess article distributed under the terms of the Creative Commons Attribution License (CC BY). The use, distribution or reproduction in other forums is permitted, provided the original author(s) and the copyright owner(s) are credited and that the original publication in this journal is cited, in accordance with accepted academic practice. No use, distribution or reproduction is permitted which does not comply with these terms. 